\title{
Positron Emission Tomography/Computed Tomography Findings of Granulocyte Colony-stimulating Factor-producing Lung Cancer
}

\author{
Yoshio Okano ${ }^{1}$, Atushi Morishita ${ }^{2}$, Keishi Naruse ${ }^{3}$ and Eiji Takeuchi ${ }^{4}$
}

Key words: PET/CT, G-CSF-producing tumor, pulmonary sarcomatoid carcinoma, bone marrow FDG uptake

(Intern Med Advance Publication)

(DOI: 10.2169/internalmedicine.8777-21)
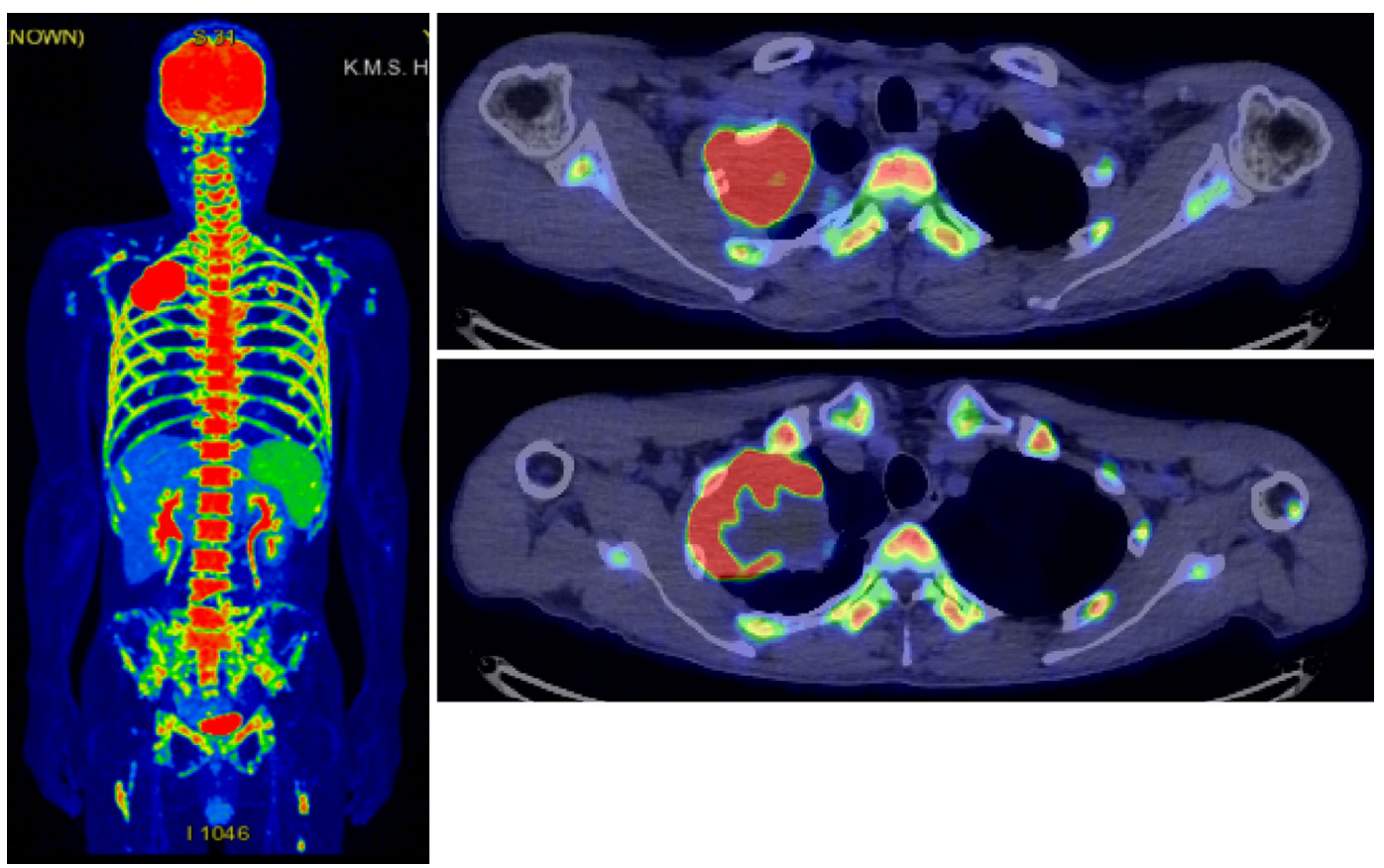

Picture 1.

A 52-year-old man was referred to our hospital with right back pain. Chest computed tomography revealed a mass in the right upper lobe. Blood tests showed marked leukocytosis with a predominance of neutrophils (white blood cells

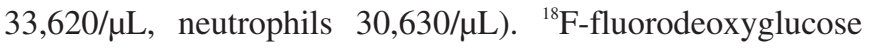
(FDG)-positron emission tomography/computed tomography (PET/CT) showed a very high FDG uptake in the right upper lobe and bone marrow throughout the body (Picture 1). However, bone metastasis was ruled out by bone marrow as- piration. The patient underwent right upper lobectomy. The final diagnosis was granulocyte colony-stimulating factor (G-CSF)-producing pulmonary sarcomatoid carcinoma (Picture 2A-D) pT4pN0cM0 stage IIIA. After tumor resection, the neutrophil and leukocyte counts and PET/CT findings normalized. A relationship has been reported between $\mathrm{G}$ CSF and the bone marrow FDG uptake (1). The FDG uptake on PET/CT reflects cellular glucose metabolism, which is caused by the G-CSF-induced enhancement of granulo-

\footnotetext{
${ }^{1}$ Department of Respiratory Medicine, National Hospital Organization Kochi Hospital, Japan, ${ }^{2}$ Department of Thoracic Surgery, National Hospital Organization Kochi Hospital, Japan, ${ }^{3}$ Department of Pathology, National Hospital Organization Kochi Hospital, Japan and ${ }^{4}$ Department of Clinical Investigation, National Hospital Organization Kochi Hospital, Japan

Received: October 4, 2021; Accepted: November 11, 2021; Advance Publication by J-STAGE: December 28, 2021

Correspondence to Dr. Eiji Takeuchi, eijitake1964@icloud.com
} 


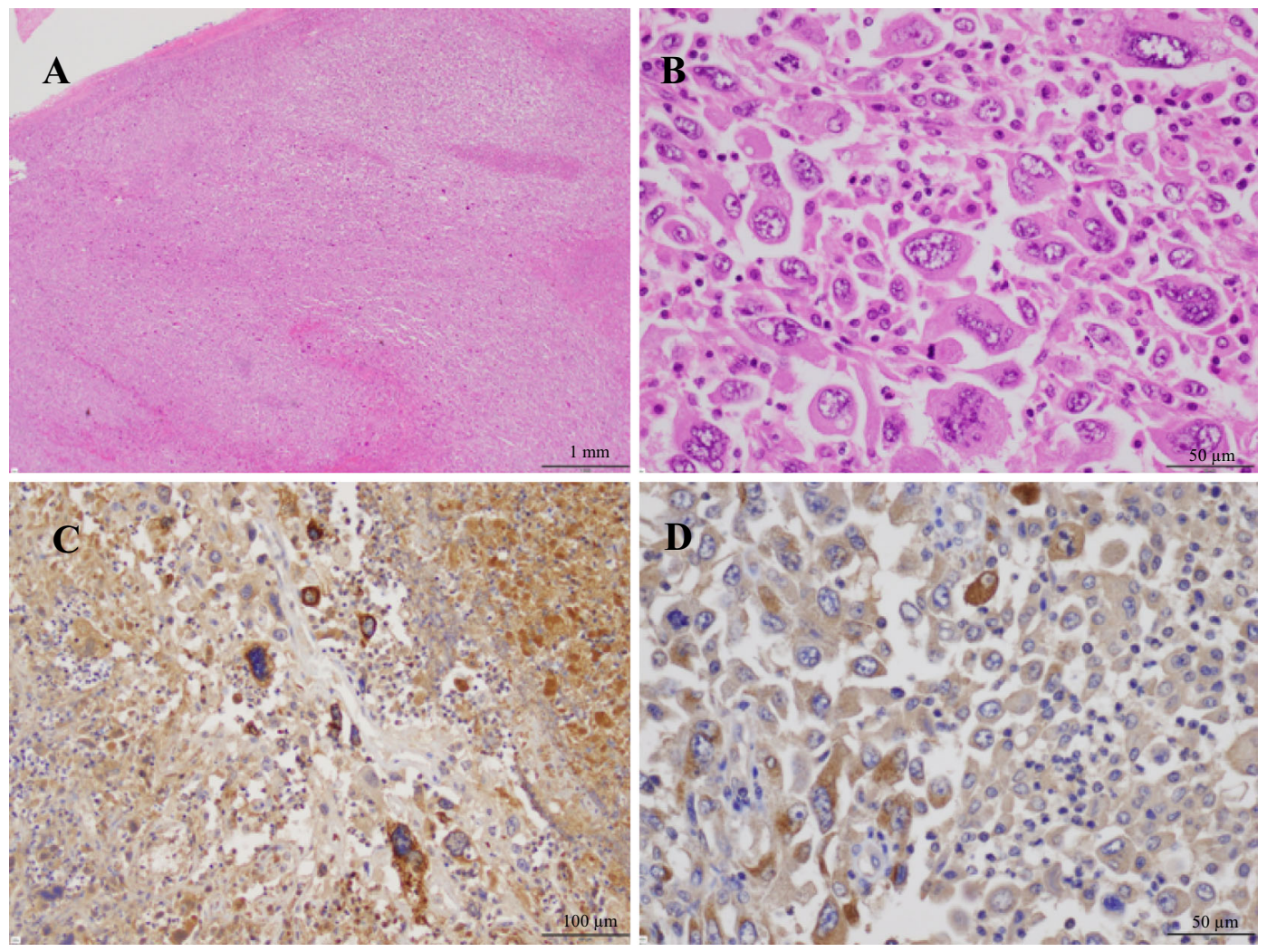

Picture 2.

cyte hematopoiesis and glucose metabolism in bone marrow. Morooka et al. reported that a diffuse and markedly elevated FDG uptake in bone marrow may facilitate a diagnosis of a G-CSF-producing tumor (2). It is important to avoid a misdiagnosis of diffuse bone metastasis.

The authors state that they have no Conflict of Interest (COI).

\section{Statement of Ethics}

All procedures performed involving human participants were in accordance with the ethical standards of the institutional and/ or national research committee and with the 1964 Declaration of Helsinki and its later amendments or comparable ethical standards. Informed consent was obtained from the patient for the acquisition and archiving of radiological data and its usage for academic purposes including publishing. No studies with animals were performed by any of the authors.

\section{References}

1. Sugawara Y, Fisher SJ, Zasadny KR, Kison PV, Baker LH, Wahl RL. Preclinical and clinical studies of bone marrow uptake of fluorine-1-fluorodeoxyglucose with or without granulocyte colonystimulating factor during chemotherapy. J Clin Oncol 16: 173-180, 1998.

2. Morooka M, Kubota K, Murata Y, et al. (18)F-FDG-PET/CT findings of granulocyte colony stimulating factor (G-CSF)-producing lung tumors. Ann Nucl Med 22: 635-639, 2008.

The Internal Medicine is an Open Access journal distributed under the Creative Commons Attribution-NonCommercial-NoDerivatives 4.0 International License. To view the details of this license, please visit (https://creativecommons.org/licenses/ by-nc-nd/4.0/).

\section{(C) The Japanese Society of Internal Medicine} Intern Med Advance Publication 